\title{
CONFUSION WITH DIFFUSION? UNRAVELLING IS DIFFUSION AND INNOVATION LITERATURE WITH A FOCUS ON SMES
}

\author{
For correspondence: \\ Jeanette K Van Akkeren \\ Lecturer in Information Systems \\ University of the Sunshine Coast \\ Locked Bag No. 4 \\ MAROOCHYDORE D.C. QLD 4558 \\ Dr. Angele L M Cavaye \\ Senior Lecturer in Information Systems \\ University of Southern Queensland \\ TOOWOOMBA QLD 4530
}

\begin{abstract}
The aim of this paper is to contribute to understanding of the various models used in research for the adoption and diffusion of information technology in small and medium-sized enterprises (SMEs). Starting with Rogers' diffusion theory and behavioural models, technology adoption models used in IS research are discussed. Empirical research has shown that the reasons why firms choose to adopt or not adopt technology is dependent on a number of factors. These factors can be categorised as owner/manager characteristics, firm characteristics, and other characteristics. The existing models explaining IS diffusion and adoption by SMEs overlap and complement each other. This paper reviews the existing literature and proposes a comprehensive model which includes the whole array of variables from earlier models.
\end{abstract}

\section{INTRODUCTION}

There is a large body of literature about the adoption of innovations in general; there is also a significant amount written about the adoption of technology and information technology (IT) in particular. Within the area of literature discussing diffusion of technology and adoption of IT, there are papers focusing on adoption by organisations and articles focusing on adoption by individuals. These two types of adoption both play a role when investigating the diffusion and adoption of IT by small and medium-sized enterprises (SMEs). After all, SMEs are small organisations where many of the decisions are made by the owner/manager. The organisational decision to adopt technology becomes intertwined with the personal perceptions and attitudes of the owner/manager towards that technology.

This paper reviews the existing literature concerning the adoption of innovation and adoption of IT by discussing the different approaches that have been taken and the various models that have emerged. Focusing on adoption of IT by SMEs, many variables and explanations of factors said to inhibit or facilitate the adoption of IT can be identified. The purpose of the paper is to build a comprehensive framework of the factors associated with the adoption of IT by SMEs. Such a framework can be used as a summary of existing literature and can form the basis of subsequent empirical enquiry.

Before embarking on the discussion of adoption models, it is useful to define the main concepts relating to this area of literature: technology, technological change, adoption, innovation, invention, and diffusion.

Technology can be defined as the use of pieces of knowledge, both practical and theoretical, in a productive manner producing given goods and services (Bannock et al. 1984). It includes the use of know-how, methods, procedures, experience of success and failures, and also physical devices and equipment. Technological change is viewed as an innovative process where firms build upon their existing knowledge base and on other assets when they search for new opportunities (Alange et al. 1998). Lundvall (1992) adds that technological change is a learning process, which is gradual and cumulative in nature. Adoption can be defined as the taking up of an idea through the approval or acceptance of that idea. Bannock et al (1984) describes innovation as the introduction of new products or production processes in the last stage of invention (invention being the discovery or devising of new products and processes). Coombs et al (1987) suggests that the term diffusion relates to the level of adoption of an innovation as a ratio of adopters to non-adopters in an industry.

This paper reviews Rogers' original Diffusion of Innovation theory highlighting the characteristics identified as most pertinent to technology adoption and diffusion. Following this, models using theories of behaviour applied by other researchers are analysed. Then, research highlighting adoption factors is discussed. Finally, a research model is presented; the model incorporates the factors identified in existing literature as impacting on technology adoption by SMEs. 


\section{ADOPTION AND DIFFUSION MODELS}

This section outlines Rogers' Diffusion of Innovations theory including the identification of the characteristics of innovation and the logistic diffusion curve. Following this, models based on theories of behaviour are presented and briefly reviewed.

\section{Rogers' Diffusion of Innovations theory}

Rogers posited Diffusion of Innovation (DOI) theory in 1962 and he and other researchers have since completed work resulting in the modification of his original theory (Rogers 1962, 1971, 1983, 1995). Rogers (1995) suggests that characteristics of innovations help persuade potential adopters to embrace or reject an innovation. The DOI model has its primary focus on how potential adopters perceive a technology in terms of relative advantage/disadvantage of an innovation (Rogers 1995). The five characteristics of an innovation identified by Rogers (1995, pp.15-16) are:

- relative advantage - the degree to which an innovation is perceived as better than the idea it supersedes;

- compatibility - the degree to which an innovation is perceived as being consistent with the existing values, past experiences, and the needs of potential adopters;

- complexity - the degree to which an innovation is perceived as difficult to understand and use;

- trialability - the degree to which an innovation may be experimented with on a limited basis;

- observability - the degree to which the results of an innovation are visible to others.

The chance of a firm adopting an innovation and the extent of that adoption is largely dependent on the characteristics of the innovation as perceived by the adopting firm (Premkumar et al. 1994).

The diffusion of innovation over time follows an S-curve shape. Coombs et al. (1987) suggest that the risk associated with the innovation decreases as more firms adopt and explains the move upwards in the S-curve. This diffusion process can be mathematically represented as $d[x(t)] / d t$, where $t$ is time and $d[\mathrm{x} t]$ is the rate of diffusion. Adoption can then be graphically represented in the form of a logistic diffusion curve as shown in Figure 1. In the logistics curve the rate of diffusion first increases up to an inflection point, and then decreases (Coombs et al. 1987).

Different innovations will have different rates of adoption which means that the slope of the S-curve can be flat or have a sharp incline. Different firms may be interested in different types of technology. Firms tend to improve and to diversify their technology by searching in zones that enable them to use and build on their existing technological base (Dosi 1988).

There are very few studies in information systems (IS) that use Rogers' DOI theory directly. Models focusing on the adoption of IT are based on Rogers original work and also take account of other original work outside the area of IS. It is this other work that is discussed next.

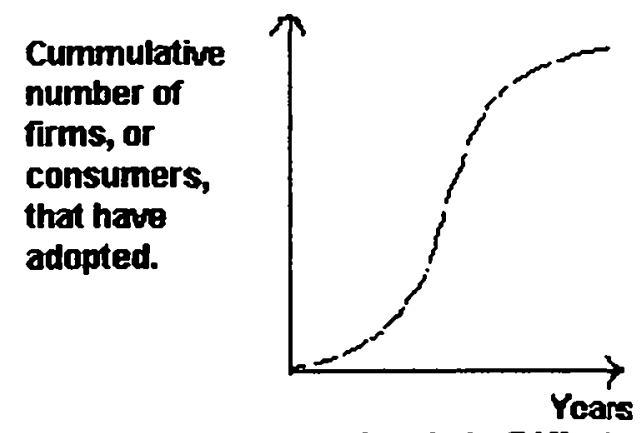

Figure 1: Logistic Diffusion Curye

\section{Behavioural theory and adoption models}

Another area of literature that has influenced IS adoption researchers consists of publications highlighting theories of behaviour. The main constructs in these theories are individual behavioural characteristics like perception and attitude. 
Ajzen (1991) discusses the Theory of Planned Behaviour (TPB) which extends his original work on the Theory of Reasoned Action (TRA). In the Theory of Planned Behaviour model, behaviour is a direct function of behavioural intention and perceived behavioural control. He further suggests that behavioural intention is formed by one's attitude, subjective norm (that is, social influences) and perceived behavioural control. Ajzen (1991) acknowledges limitations with the Theory of Planned Behaviour model, in particular, that the relationship between the belief structures and the determinants of intention are not particularly well understood causing some inconsistency in results.

Taylor and Todd (1995) suggest an alternative version to the Theory of Planned Behaviour model called the Decomposed Theory of Planned Behaviour. This model attempts to overcome limitations of the Ajzen (1991) version particularly in relation to attitudinal, normative and control beliefs that are decomposed into multidimensional belief constructs (Taylor and Todd 1995). Problems with operationalising the earlier model are overcome as relationships become clearer and more readily understood, pointing to specific factors that may influence technology adoption and usage. These factors include the perceived characteristics of an innovation, relative advantage, and compatibility of the innovation to the adopter's existing values, previous experiences and current needs (Taylor and Todd 1995).

Davis (1989) puts forward the Technology Acceptance Model (TAM) which addresses IT adoption, implementation and diffusion in terms of perceived ease of use and perceived usefulness. The causal model hypothesises that actual systems use is affected by behavioural intentions that are themselves affected by attitudes toward use. Gefen and Straub (1997) suggest that belief about the system, perceived use and perceived ease of use, directly affects attitudes toward use. One limitation of the TAM is that the model excludes the influence and personal control factors on behaviour. In addition, economic factors or outside influences (suppliers, customers, competitors) are not specifically addressed in this model.

\section{MODELS FOCUSING ON IT ADOPTION BY SMES}

There is a relatively small but significant body of literature that focuses on the adoption and use of IT by SMEs. Small and medium-sized enterprises are significantly different from large organisations and SME characteristics affect their ability and willingness to adopt IT. Large organisations generally have the funding, resources and expertise to pursue technology innovation and adoption, or if not, can outsource the needed expertise. In comparison, small businesses have to rely on a small number of employees, and are further constrained in terms of time and capital availability.

The problem of resource poverty has been recognised for some time, but recent research shows that this remains a major difficulty when it comes to SMEs adopting IT. For instance, DeLone (1988) shows that inadequate financial resources, inadequate managerial time, and lack of internal expertise discouraged IT growth in SMEs. Similarly, Lawrence (1997), in an exploratory study of SMEs in Tasmania, found that many SMEs were not readily incorporating new technologies into their business. The level of sophistication of a firm in terms of IT usage and knowledge appears to impact heavily on whether technology will or will not be adopted. Recent research indicates that reluctance to adopt innovations can be attributed to factors such as resource poverty, lack of IT knowledge, and a perception of a lack of business benefit (Julien and Raymond 1994, Kirby and Turner 1993, Yellow Pages Australia 1997).

A number of IT adoption models based on empirical data bout SMEs have been put forward (Julien and Raymond 1994, Brooksbank et al 1992, Kirby and Turner 1993, Iacovou et al. 1995, Thong and Yap 1995, Harrison et al. 1997, Gefen and Straub 1997). Following is a review of the recent literature.

Iacovau et al (1995) based their model on Roger's work, particularly in relation to relative advantage and trialability, with perceived benefits and impact of technology as adoption factors. In addition, they identified the following factors as affecting technology adoption:

- organisational readiness (financial and technological resources of the firm), and

- external pressure to adopt (from competitors and trading partners).

Behavioural and attitudinal factors, and firm characteristics in terms of size, sector, status and complexity, are not clearly addressed in this study as determinants of technology adoption in small business.

A model developed by Kirby and Turner (1993) suggests the following factors as impacting technology adoption:

- the computer literacy of the small business owner,

- lack of knowledge of benefits derived from IT, and

- dependency of the small customer on the supplier.

However, constructs measuring technology adoption and acceptance are limited given the models previously developed and tested in the IT literature.

Using similar constructs to Kirby and Turner (1993) is the model developed by Julien and Raymond (1994). This model includes another three factors thought to influence new technology adoption in small business:

- structural sophistication of the firm in terms of centralisation and complexity; 
- the level of assertiveness, rationality and interaction in business decision processes;

- size, sector, and status of the firm (independent or affiliated).

Again this model is limited in terms of the number of constructs previously shown in IT literature to influence technology adoption, with many factors not included in the research design, for example, perception, attitude, and economic factors.

Another model developed by Thong and Yap (1995) uses two main categories of factors influencing IT adoption in SMEs. They are:

- individual characteristics (CEO innovativeness, attitude towards adoption of IT, and IT knowledge);

- organisational characteristics (business size, competitiveness of environment, information intensity).

However, perceived control of IT adoption (an important factor for the owner/manager), and structural sophistication of the firm (its ability to incorporate new technologies into its work practices) are ignored in this study.

Finally, Harrison et al (1997) use an extension of the Theory of Planned Behaviour model, similar in context to factors used by the Thong and Yap (1995) study, to explain and predict a small business executive's decision to adopt information technology. Factors in their model include both owner/manager characteristics and firm characteristics:

- decision processes based on attitude;

- subjective norm;

- perceived control regarding IT adoption;

- firm size, sector and status; and

- individual characteristics.

A limitation of many studies is that they do not include return on investment. Financial issues are vitally important to owner/managers and often drive technology adoption in small firms. An innovative SME owner may recognise all the benefits to his firm in adopting IT in terms of both a short- or long-term investment.

However, without sufficient funding the owner cannot adopt.

Return on investment is addressed by Economics of Technology (EOT) theory which is based on the returns on investing in an innovation for a firm. Fichman and Kemerer (1993) discuss the effects of IT investment in terms of four determining characteristics: prior technology drag, irreversibility of investments, sponsorship, and expectations. However, EOT theory does not capture firm characteristics (external pressures to adopt, the sector and status of the organisation) or the DOI perceptions of the owner/manager. Firm characteristics are generally of an economic nature, and not addressed in the DOI model or EOT theory. Since empirical studies have determined these factors as influencing technology adoption in SMEs, it would be useful to include them in a general IT adoption model.

\section{FACTORS AFFECTING IT ADOPTION IN SMES}

Many different factors have been identified in the literature as affecting IT adoption by SMEs. The factors identified in the studies reviewed above can be separated into two main categories: owner/manager characteristics and firm characteristics, with the addition of return on investment as an influencing factor. The owner/manager category includes views and perceptions of the owner/manager about the use and usefulness of IT for the SME; firm characteristics include factors relating to the size of the firm, the position of the SME in its industry, and other characteristics of individual organisations. Table 1 (following page) identifies individual factors for each category and their source. 


\begin{tabular}{|c|c|c|}
\hline Category & W Individual Factor & 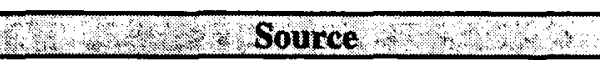 \\
\hline \multirow[t]{5}{*}{$\begin{array}{l}\text { Owner/Manager } \\
\text { Characteristics }\end{array}$} & $\begin{array}{l}\text { - Perceived benefits (ease of use, } \\
\text { usefulness) }\end{array}$ & $\begin{array}{l}\text { Iacovau et al. (1995), Kirby and Turner } \\
\text { (1993), Thong and Yap (1995) }\end{array}$ \\
\hline & $\begin{array}{l}\text { Computer literacy of business } \\
\text { owner }\end{array}$ & $\begin{array}{l}\text { Kirby and Turner (1993), Thong and } \\
\text { Yap (1995) }\end{array}$ \\
\hline & $\begin{array}{l}\text { Level of assertiveness, } \\
\text { rationality and interaction of } \\
\text { business decision processes }\end{array}$ & $\begin{array}{l}\text { Julien and Raymond (1994), Harrison et } \\
\text { al. (1997) }\end{array}$ \\
\hline & $\begin{array}{l}\text { - } \begin{array}{l}\text { Perceived control regarding IT } \\
\text { adoption }\end{array} \\
\text { a }\end{array}$ & Harrison et al. (1997) \\
\hline & Subjective norm & Harrison et al. (1997) \\
\hline \multirow[t]{7}{*}{$\begin{array}{c}\text { Firm } \\
\text { Characteristics }\end{array}$} & - Organisational readiness & Iacovou et al. (1995) \\
\hline & - External pressure to adopt & $\begin{array}{l}\text { Thong and Yap (1995), Iacovau et al } \\
\text { (1995) }\end{array}$ \\
\hline & $\begin{array}{l}\text { Dependency of the small } \\
\text { business customer on } \\
\text { supplier(s) }\end{array}$ & Kirby and Turner (1993) \\
\hline & $\begin{array}{l}\text { Structural sophistication of the } \\
\text { firm in terms of centralisation } \\
\text { and complexity }\end{array}$ & $\begin{array}{l}\text { Julien and Raymond (1994), Harrison et } \\
\text { al. (1997) }\end{array}$ \\
\hline & - $\quad$ Sector & $\begin{array}{l}\text { Julien and Raymond (1994), Harrison et } \\
\text { al. (1997) }\end{array}$ \\
\hline & - $\quad$ Status & $\begin{array}{l}\text { Thong and Yap (1995), Julien and } \\
\text { Raymond (1994), Harrison et al. (1997) }\end{array}$ \\
\hline & - Information intensity & Thong and Yap (1995) \\
\hline Other Factors & - Return on investment & Fichman and Kemerer (1993) \\
\hline
\end{tabular}

Table 1: Summary of factors influencing IT adoption in SMEs

The effects of each characteristic on SME IT adoption or non-adoption are discussed below; sources will not be repeated as they can be found in table 1 .

\section{Owner/Manager Characteristics}

- Perceived benefits affect technology adoption in terms of the perceived ease of use and/or usefulness of the technology. If an owner/manager does not perceive the technology in a positive way, he/she will be reluctant to adopt.

- The computer literacy of the business owner can also influence technology adoption. If the owners are unaware or do not understand the technologies available, they are unlikely to adopt them into their own business.

- The level of assertiveness, rationality and interaction of business decision processes can also impact on IT adoption. If owners of the firm are assertive in business decision processes, understands the benefits and uses of the technology to their organisation, and are able to rationalise that information, they will be more likely to adopt IT.

- Perceived control relates to the amount of requisite opportunities and resources (time, money, skills, co-operation of others) someone possesses to be able to carry out the course of action (technology adoption). For example, a small business owner may decide that connection to the Internet is an important competitive use of IT. Yet if there is a possible budget shortfall, their decision to adopt will be influenced.

- Subjective norm is thought to affect technology adoption in terms of the strength of the person's normative beliefs that 'groups' think the behaviour of interest (technology adoption) should or should not be performed, multiplied by a person's motivation to comply with the group. 


\section{Firm Characteristics}

- Organisational readiness refers to the level of technology currently incorporated into business processes. If there is little technology incorporated, or outdated/inefficient technology being utilised, a firm is less likely to adopt new technologies.

- A SME will be reluctant to adopt innovative IT unless there is a specific request for it by their trading partners and/or customers. If this external pressure to adopt IT is not present in the industry sector, then the business owner may perceive the technology as a waste of resources.

- The dependency of the small business customer on the supplier is linked to the previous factor. Not only would the supplier need to have adopted the technology to make it viable, the SME owner would need to recognise and understand the benefits to his or her firm in adopting the technology. In addition, an organisation may perceive that their clientele was of a certain socio-economic level that would not readily benefit from the introduction of new technologies.

- The structural sophistication of the firm in terms of centralisation and complexity will also influence technology adoption in its ability to incorporate new technologies into its work practices. A particularly complex structure could either inhibit or facilitate technology adoption and would be dependent on whether the owner believed that IT could be easily incorporated and enhance operations, or excessively disrupt operations.

- The sector that an organisation belongs to affects IT adoption some industry groups embracing technological innovation and others reluctant to adopt. If competitors and trading partners within the sector have adopted IT, an owner may be more inclined to adopt as well. The Yellow Pages Australia (1997) findings indicated that the business services sector, manufacturing sector, and transportstorage sectors were the most innovative in terms of technology adoption. In contrast, building/construction and personal service sectors ranked low in their adoption of IT with adoption inhibitors identified as including a lack of perceived benefits, a fear that technologies would waste staff time, lack of IT knowledge/skills, and the cost of the technology.

- Another factor that has been shown to impact on the rate of SME technology adoption is the status of the organisation: whether the organisation is franchised or otherwise connected to partner organisations, or completely independent. Treadgold (1990) found that small retail businesses with high IT adoption rates had been influenced by trade associations, wholesalers, and franchisors that encouraged IT adoption.

- Finally, the level of information intensity within the organisation may influence the owner to adopt or not adopt a technology. For example, if large amounts of data and information are part of the business processes, an owner may be more likely to adopt technologies that could streamline operations and lead to process efficiencies within the organisation.

\section{Other Factors}

- The need by SME owners for an immediate return on investment is due to the necessity to be concerned with medium-term survival rather than the long-term attainment of market share. To make a substantial outlay of capital resources, the owner would need to see exactly where the return was going to be in the short-term.

\section{A RESEARCH MODEL FOR INVESTIGATING IT ADOPTION BY SMEs}

DOI theory, the Technology Acceptance Model, Theory of Planned Behaviour, and Decomposed Theory of Planned Behaviour, generally support factors in the 'owner/manager characteristic' category. The focus of these early adoption models is perceptions, attitudes and beliefs. More recent literature adds enhancements to these earlier models including additional constructs thought to impact on technology adoption and diffusion such as economic factors and firm characteristics (e.g. Thong and Yap 1995, Julien and Raymond 1994, Harrison et al 1997).

The various IT adoption models identify many factors affecting IT adoption in SMEs. The models overlap and complement one another. Determining constructs that are most pertinent to technology adoption by the SME owner/manager requires the integration of a combination of factors identified in prior studies. A comprehensive model of factors affecting the adoption of IT by SME owner/managers is presented in figure 2 . 


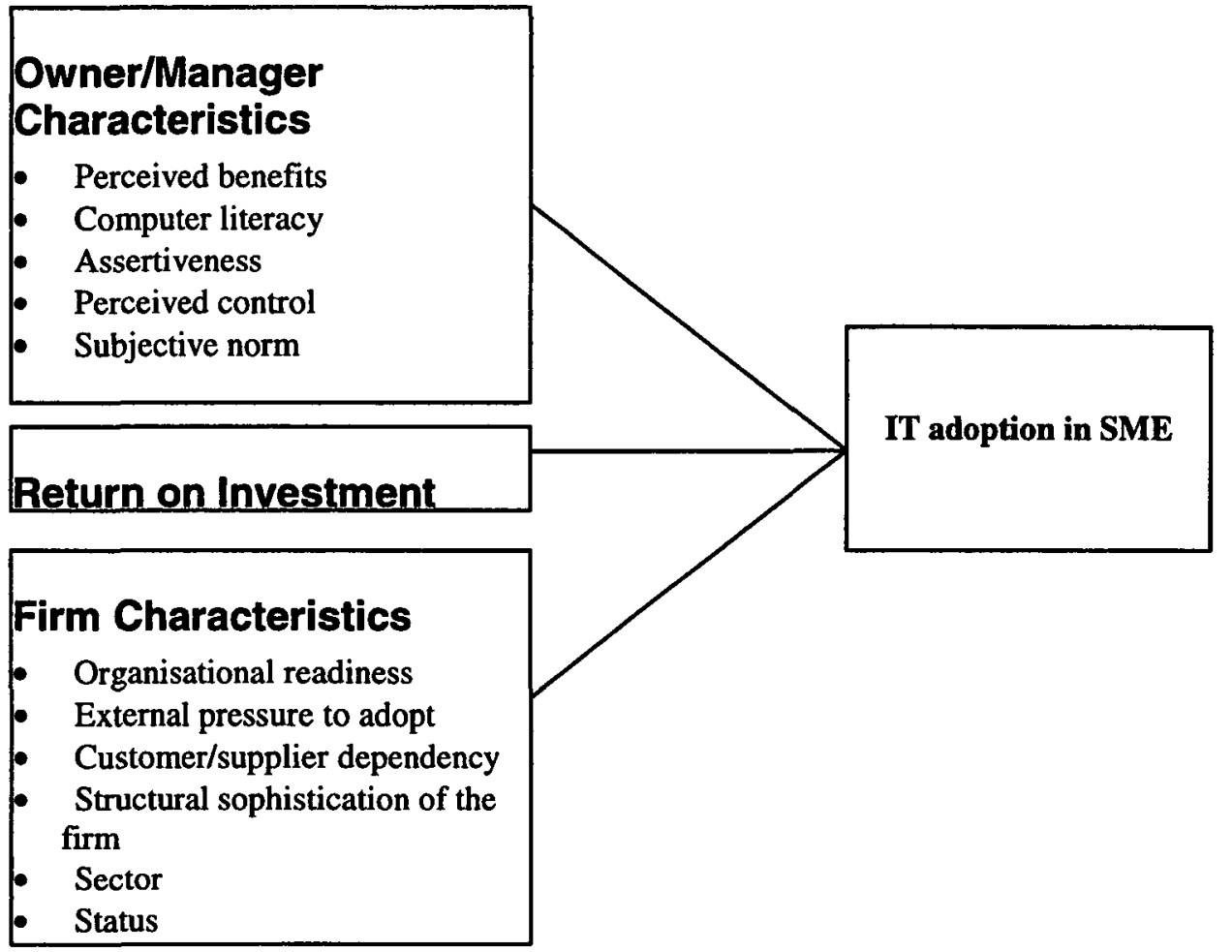

Figure 2: Factors affecting IT adoption in SMEs

This model attempts to capture and summarise all factors identified from the literature as affecting technology adoption by SMEs. In addition to these there may be other factors not previously identified that affect technology adoption in SMEs. Further research may uncover additional constructs not yet listed in the model in figure 2 .

\section{CONCLUSION}

This paper has reviewed and summarised those factors thought to affect adoption of information technology in SMEs. Since Rogers posited his Diffusion of Innovation theory more than 25 years ago, there have been a number of models used to identify characteristics of technology adoption. Some of these models are based closely on Rogers work; others have used constructs identified after empirical research. None of the previous models attempt to capture all factors shown in the literature to impact on whether a firm will adopt or will not adopt IT. Figure 2 presents a research model comprising all the factors identified in existing literature that have been shown to affect IT adoption by SMEs. The model is intended as a summary of current findings and as a framework that may be used by future researchers.

There are opportunities for further research into factors that facilitate or inhibit an SME owner/managers decision on whether to adopt IT. One avenue for further research is the identification of other adoption factors. The proposed model may not be complete and there may be additional factors potentially affecting IT adoption. Further research could also use the model as a basis for investigating the adoption of new technologies by SMEs. The individual factors in figure 2 could then act as a guide when investigating inhibitors to the adoption of a particular technology by SMEs. For instance, Internet technologies have the potential to 'level the playing field' for SMEs, but recent surveys show that Australian SMEs have been slow to adopt them (Yellow Pages Australia 1997, Forrester Research 1997). Studies could investigate the reasons for slow adoption and look at ways to overcome inhibitors to adoption. 


\section{REFERENCES}

Ajzen, I. 1991, "The theory of planned behaviour", Organisational Behaviour and Human Decision Processes, pp. 179-211 in Taylor, S. and Todd, P.A. 1995, 'Understanding information technology Usage: A test of competing models', Information Systems Research, June, vol. 6, no. 2, pp.144 -176

Alange, S., Jacobsson, S., and Jarnehammer, A. 1998, "Some aspects of an analytical framework for studying the diffusion of organisational innovations", Technology, Analysis and Strategy, March, vol.10, no.1, pp. 3-21

Bannock, G., Baxter, R.E., and Rees, R. 1984, The Penguin Dictionary of Economics, $3^{\text {rd }}$ edn, Penguin Books, England

Brooksbank, R., Kirby, D., and Kane, S. 1992, "IT adoption and the independent retail business: The retail newsagency", International Small Business Journal, Apr-Jun, vol. 10, no. 3, pp. 53-61

Coombs, R., Saviotti, P., and Walsh, V. 1987, Economics and Technological Change, MacMillan Education Limited, London

Davis, F., 1989, "Perceived usefulness, perceived ease of use and user acceptance of information technology", MIS Quarterly, September, vol. 13, no. 3, pp. 319-340.

DeLone, W.H. 1988, "Determinants of success for computer usage in small business", MIS Quarterly, March, vol. 12 , no. 1, pp. 51-61

Dosi, G. 1988, "Sources, procedures and microeconomic effects of innovation", Journal of Economic Literature, vol. 26, pp. 1120-1171

Fichman, R. G. and Kemerer, C.F. 1993, "Adoption of software engineering process innovations: The case of object-orientation", Sloan Management Review, Winter, pp. 7-22

Forrester Research Incorporated, Forrester ranks world economics for eCommerce, 30 April 1997 , Cambridge, MA, [online] <http://www.forrester.com.>, accessed August 1998.

Gefen, D., and Straub, D.W. 1997, "Gender differences in the perception and use of E-mail: An extension to the technology acceptance model", MIS Quarterly, December, vol.21, no. 4, pp. 389-400.

Harrison, D.A., Mykytyn, P.P. .Jr, and Rienenschneider, C.K. 1997, "Executive decisions about IT adoption in small business: Theory and empirical tests", Information Systems Research, A Journal of the Institute of Management Sciences, June, vol. 8, no. 2, pp. 171-195

Iacovou, C.L., Benbasat, I., and Dexter, A.A. 1995, "Electronic data interchange and small organisations: Adoption and impact of technology", MIS Quarterly, December, vol. 19, no. 4, pp. 465-485

Julien, P.A., and Raymond, L. 1994, "Factors of new technology adoption in the retail sector", Entrepreneurship: Theory and Practice, Summer, vol. 18, no. 5, pp. 79-90

Lawrence, K.L. 1997, "Factors inhibiting the utilisation of electronic commerce facilities in Tasmanian small- to medium-sized enterprises", $8^{\text {th }}$ Australasian conference on Information Systems, October

Lundvall, B.A. 1992, National Systems of Innovation. Towards a Theory of Innovation and Interactive Learning, Francis Pinter, London.

Kirby, D., and Turner, M. 1993, "IT and the small retail business", International Journal of Retail and Distribution Management, vol. 21, no. 7, pp. 20-27

Premkumar, G., Ramamurthy, K., and Nilakanta, S. 1994, "Implementation of electronic data interchange: An innovation diffusion perspective", Journal of Management Information Systems, Fall, vol. 11, no. 2, pp. 157-186

Rogers, E.M. 1995, Diffusion of Innovations, $4^{\text {th }}$ edn, The Free Press, New York.

Taylor, S. and Todd, P.A. 1995, "Understanding information technology Usage: A test of competing models", Information Systems Research, June, vol. 6, no. 2, pp.144 -176

Thong, J. and Yap, C.S. 1995, "CEO characteristics, organisational characteristics, and information technology adoption in small business", Omega, August, vol. 23, no. 4, pp. 429-442

Treadgold, A., 1990, "The role of distribution channel agents in promoting innovative activity in small retail businesses: A case study of IT adoption", Service Industries Journal, vol. 10, no. 4, pp.651-663

Yellow Pages Australia 1997, Small Business Index: A Special Report on Technology in the Small Business Sector, August.

Yin, R.K. 1994, Case Study Research: Design and Methods, $2^{\text {nd }}$ edn, Sage Publications Inc, Thousand Oaks, CA, United States of America 